\title{
GENERATOR LIFE AND POWER ELECTRONICS
}

\author{
By: \\ K.R. Davey \\ H.E. Jordan \\ R.J. Rodriguez \\ R.E. Hebner
}

Naval Engineers Journal, vol. 123, no. 4, pp. 31-39, December 2011

PR 479.1

Center for Electromechanics

The University of Texas at Austin

PRC, Mail Code R7000

Austin, TX 78712

(512) 471-4496 


\title{
GENERATOR LIFE AND POWER ELECTRONICS
}

\author{
Kent R. Davey, Fellow, IEEE, Howard Jordan, Fellow, IEEE, Rigoberto Rodriguez, and Robert E. Hebner, \\ Fellow, IEEE
}

\begin{abstract}
The deleterious effect of full bridge rectifiers on the output of an ac generator deserves attention by the Naval community. The harmonics witnessed at the stator of the generator not only introduce hysteresis and eddy current losses, but voltage spikes which impact the life of the generator. The two primary factors compromising life are localized heating due to harmonics, and voltage spikes which cause insulation failure through partial discharge. Induced eddy currents are proportional to frequency squared.
\end{abstract}

Index Terms - efficiency, harmonics, life, thermal loss, inverter

\section{INTRODUCTION}

There are two ways that rectification presents problems to a generator. First, turning off current quickly induces L di/dt voltages earmarked by spikes. This kind of voltage degrades the insulation, contributing both to partial discharge and localized field stress. Second, the currents are no longer sinusoidal. Fourier decomposition shows that they are composed of multiple frequencies, predominantly off. These harmonic frequencies add to the electrical loss in both the rotor and stator by eddy current induction and hysteresis.

Cavallini[1] attempts to quantify the effects of a distorted waveform through two other indices which are weakly

K. R. Davey is with the University of Texas at Austin, Center for Electromechanics, 10100 Burnet Road, Austin, TX 78758, USA (phone: 512.232.1603; fax: 512.475.7700; e-mail:k.davey@mail.utexas.edu).

Howard Jordan is with the University of Texas at Austin, Center for Electromechanics, 10100 Burnet Road, Austin, TX 78758, USA (phone: 512.232.1605; fax: 512.475.7700; e-mail: hjordan99@mail.utexas.edu).

R.. E. Hebner, is with the University of Texas at Austin, Center for Electromechanics, 10100 Burnet Road, Austin, TX 78758, USA (phone: 512.232.1628; fax: 512.475.7700; e-mail: r.hebner@mail.utexas.edu).

Rigoberto Rodriguez is with the Science Applications International Corporation, (SAIC), 10100 Battleview Parkway, Suite 100 Manassas, VA. 20109-2334, phone (571)-201-4535, email : rigoberto.j.rodriguez@saic.com. linked. The first is $\mathrm{Kp}$, the ratio of the peak voltage of the distorted waveform to the sinusoidal rated voltage. The second involves a ratio of the product of the inverter switching frequency and the inverse rise time to the sinusoidal system frequency. Increasing the frequency from a nominal $50-60 \mathrm{~Hz}$ to $10 \mathrm{kHz}$ reduces insulation life by three orders of magnitude. Pillay quantifies the magnitude of the problem as it concerns induction motors fed by any unbalanced supply [2]. Any unbalance that increases the temperature by $14.3^{\circ} \mathrm{C}$ reduces the life by $55.3 \%$.

Among the better indices reflecting the magnitude of the problem is total harmonic distortion (THD), defined as

$\frac{\sqrt{\sum_{n=2}^{\infty} I_{n}^{2}}}{I_{1}}$, where $\mathrm{I}_{1}$ is the magnitude of the fundamental and $I_{n}$, the magnitude of the nth harmonic. The voltage spikes compromise the winding insulation, and the current harmonics compromise life by increased heating. It is therefore useful to index total harmonic distortion for both current and voltage.

Table I Insulation Class Ratings

\begin{tabular}{|c|c|c|c|}
\hline Class & $\begin{array}{c}\text { Max } \\
\text { Temp } \\
\left({ }^{\circ} \mathrm{C}\right)\end{array}$ & $\begin{array}{c}\text { Temp. } \\
\text { Rise }\end{array}$ & $\begin{array}{c}\text { HIC halving } \\
\text { interval }\end{array}$ \\
\hline $\mathrm{A}$ & 105 & 65 & 14 \\
\hline $\mathrm{B}$ & 130 & 90 & 11 \\
\hline $\mathrm{F}$ & 155 & 115 & 9.3 \\
\hline $\mathrm{H}$ & 180 & 140 & 8 \\
\hline $\mathrm{H}^{\prime}$ & 220 & 180 & 10 \\
\hline
\end{tabular}

Skibinski [3] has quantified motor insulation life (Fig. 1) as well as increased heating and decreased efficiency (Fig. 2) as a function of this index. The important thing to remember from these charts is that the motor life reduces to about $1 / 2$ of normal as THD approaches $30 \%$. Skibinski notes that TH-I (current) values THD-I of $25 \%$ at $>850$ $\mathrm{kVA}$ ratings to $10 \%$ at $135 \mathrm{kVA}$ is typical. THD-V (voltage) values of PWM inverters of $40 \%$ can be expected. Skibinski summarizes the information in Fig. 1 and Fig. 2 with the comment that "THD-V and THD-I of $5 \%$ or less would be desirable". 
Similar relationships have been attempted by correlating temperature increase with life reduction [4]. The Arrhenius equation has proven useful in this regard,

$$
L_{x}=L_{100} \cdot 2^{\left(T_{c}-T_{x}\right) / H I C}
$$

where $\mathrm{L}_{\mathrm{x}}=\%$ life at temperature $\mathrm{T}_{\mathrm{x}}, \mathrm{L}_{100}=\%$ life at temperature $\mathrm{Tc}, \mathrm{Tc}=$ allowed temperature for insulation, and $\mathrm{HIC}=$ halving interval for insulation. The halving interval changes for each insulation class; these are tabulated in Table I.

\section{Motor Insulation Life vs THD}

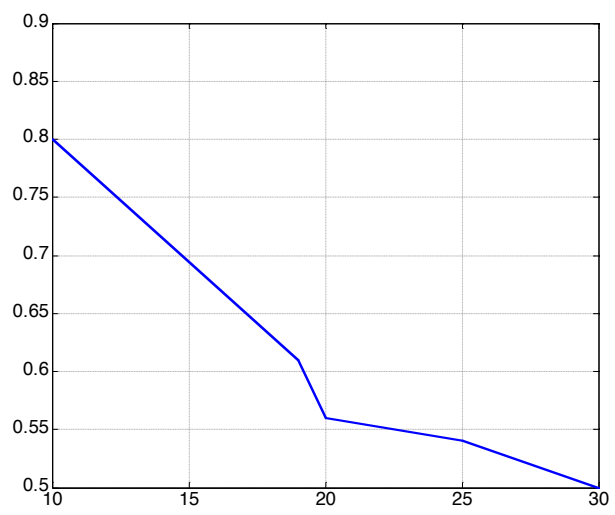

Fig. 1 Motor insulation half life decrease as a function of total harmonic distortion (THD-V).

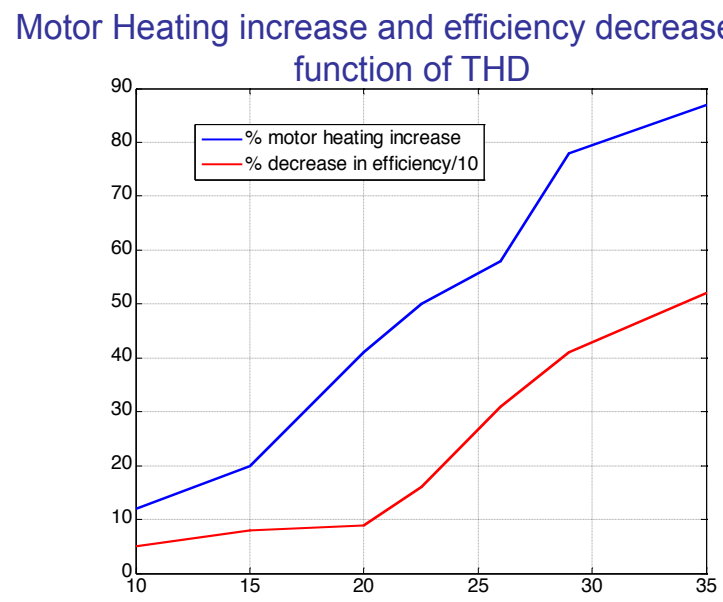

Fig. 2 motor heating and efficiency change as a function of total harmonic distortion (THD-I).
A number of techniques have been suggested for lowering the total harmonic distortion. A straightforward solution is to not employ dc, but to use an ac - ac matrix [5] or resonant converter [6] which switches through zero current crossings. Another that has been suggested is to move to a higher number of phases. A delta and a $\mathrm{Y}$ tap on the generator can be used to get a 30 degree shift between the phases. Multiple phase generation definitely helps the total harmonic distortion of the output waveform. But interruption of current at nonzero current crossings is indigenous to rectifier function.

\subsection{Simulation of three and nine phase systems}

In house simulation (Fig. 3) and experimentation show that a full three phase rectification bridge introduces $28.56 \%$ total harmonic distortion back into the generator for a loaded generator.

Consider the nine phase generator simulation shown in Fig. 4. Because simulink does not have a nine phase generator, it is necessary to use 9 separate generators and set the phase for each separately. These three waveforms are being fed in triplets to three rectifier bridges as shown. This type of setup is quite useful for reducing ripple on the dc output, in this case from an average $11 \%$ ripple for a three phase system to $3 \%$ for a nine phase system. The total harmonic distortion on the generator side is not changed much from the three phase case; it has dropped to $26.1 \%$. Note that this assumes a pure sine wave input for all nine phases without coupling between the phases. Additional work is warranted to see how this changes if coupling exists between the phases.

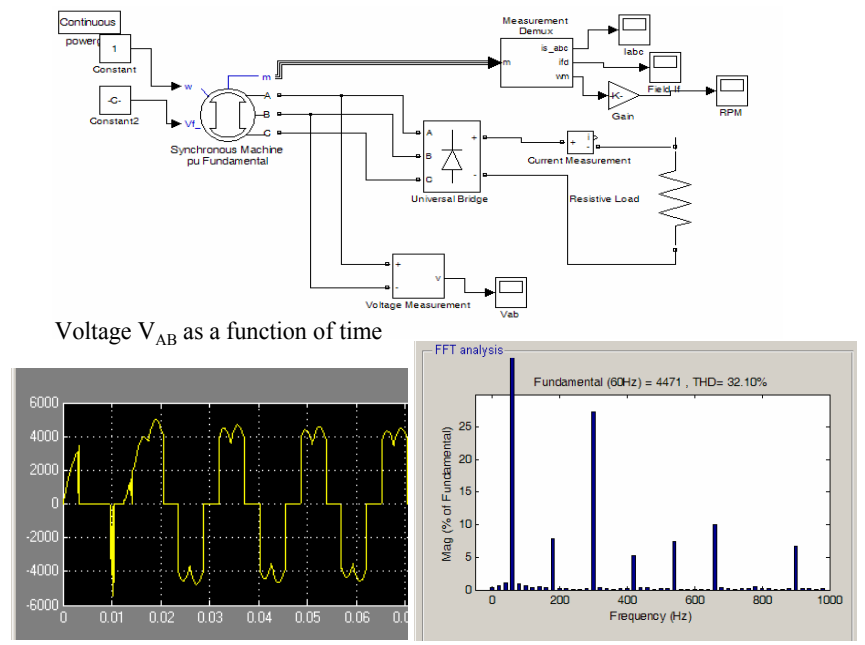

Fig. 3 Test to index the effect of a full wave bridge. 


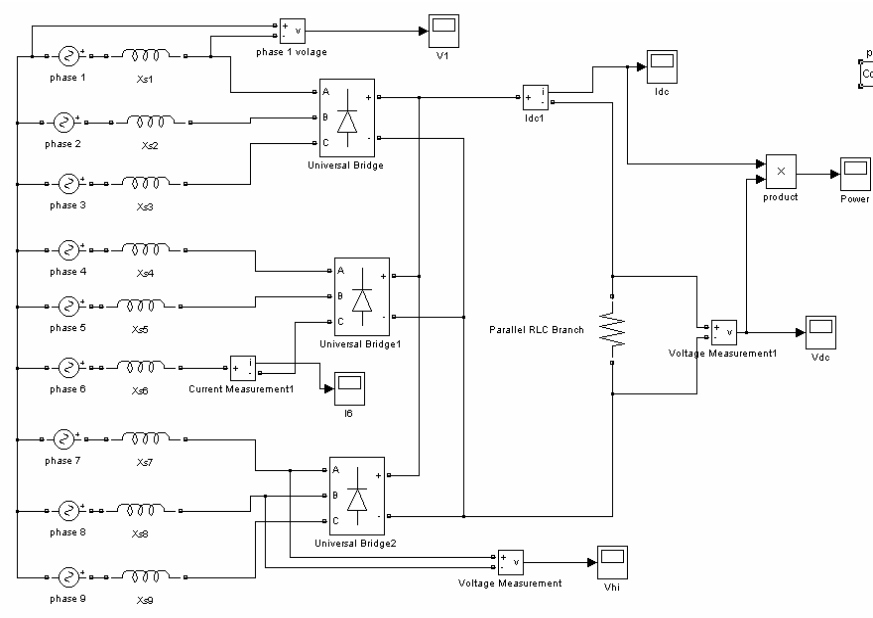

Fig. 4 Nine phase generator simulation.

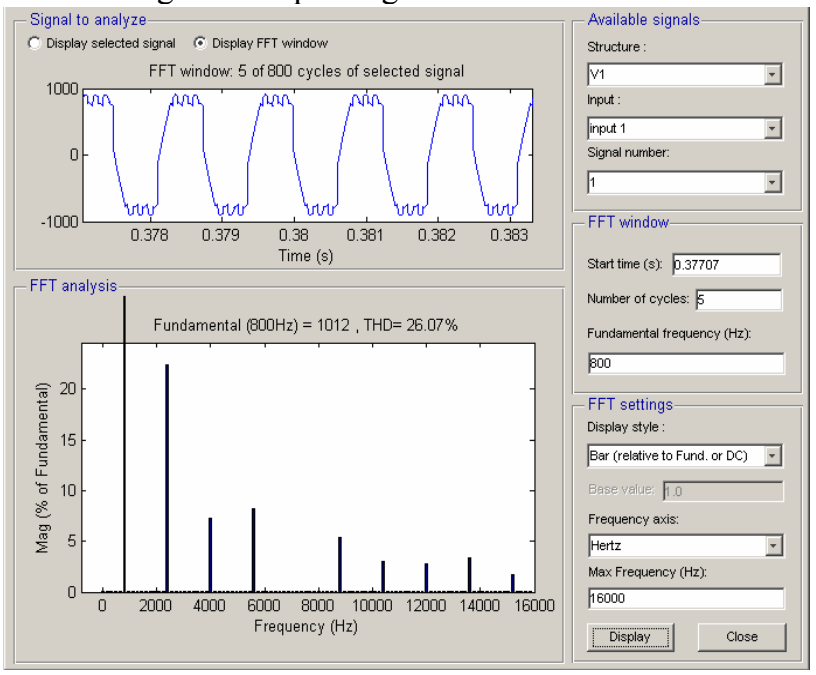

Fig. 5 Generator side voltage (v1) as a function of time.

\section{FIELD THEORY ANALYSIS OF CURRENT CHANGES IN A GENERATOR}

The current waveform commensurate with a resistive load as in Fig. 3 is shown in Fig. 6. The relative amplitudes of the different $3^{\text {rd }}, 5^{\text {th }}$, components in Fig. 3 are listed in Table II.

\section{Table II Relative amplitudes of the different current components in Fig. 6.}

\begin{tabular}{|l|l|l|l|l|l|l|}
\hline Harmonic & $\begin{array}{l}1^{\text {st }} \\
(60)\end{array}$ & $\begin{array}{l}3^{\text {rd }} \\
(180)\end{array}$ & $\begin{array}{l}5^{\text {th }} \\
(300)\end{array}$ & $\begin{array}{l}7^{\text {th }} \\
(420)\end{array}$ & $\begin{array}{l}9^{\text {th }} \\
(540)\end{array}$ & $\begin{array}{l}11^{\text {th }} \\
(660)\end{array}$ \\
\hline Voltage & 1 & 0.0785 & 0.2723 & 0.0529 & 0.0737 & 0.1004 \\
\hline Current & 1 & 0.0274 & 0.0358 & 0.0213 & 0.0092 & 0.0041 \\
\hline
\end{tabular}

Fig. 7 shows a wound rotor generator. Of interest is the rotor induced eddy loss due to the presence of these harmonics. A rotational transient analysis was conducted by assuming the rotor rotating at 1200 RPM and the stator coils excited with the currents for each harmonic scaled as shown in Table II. The fundamental has a 3000 amp-turn peak. This $875 \mathrm{~kW}$ generator would have an additional 5.5 $\mathrm{kW}$ of loss induced in the rotor just from eddy currents.
Hysteresis will add about 2.5 to $3 \mathrm{~kW}$. So we have lost another 1 percent in efficiency just due to rotor losses.

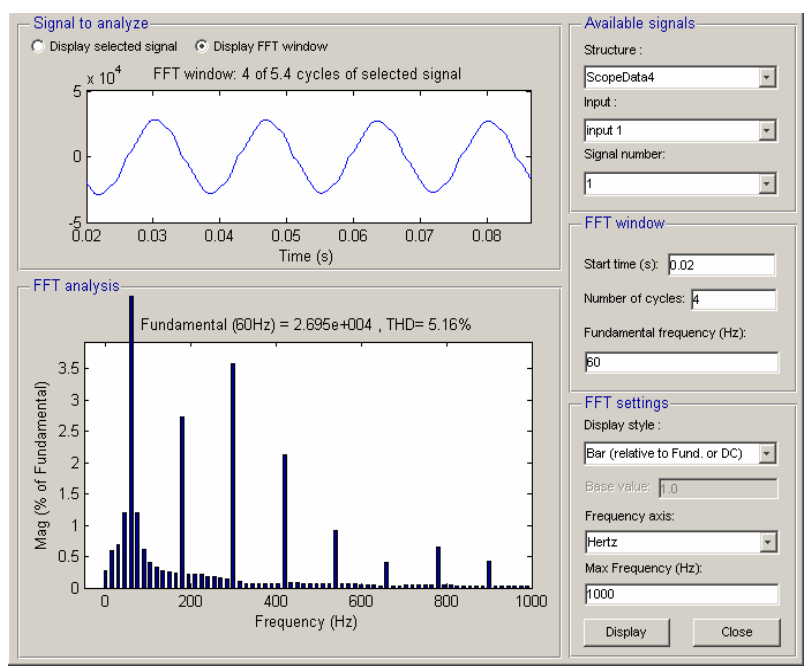

Fig. 6 Current commensurate with a generator loaded as in Fig. 3.

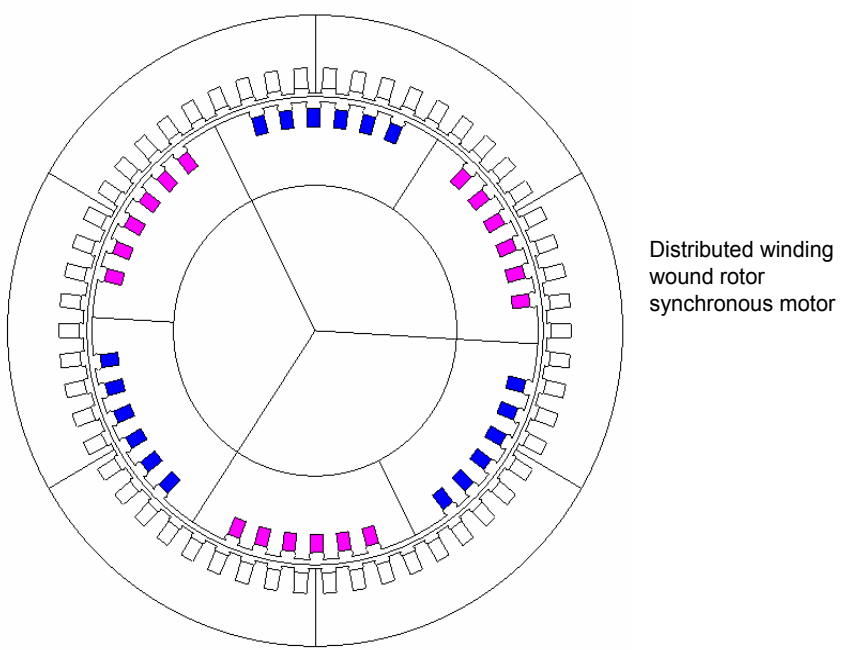

Fig. 7 Wound rotor generator used to compute the losses from the various excitation harmonics on the rotor.

\section{RESONANT CONVERTER}

The ac-ac resonant inverter shown in Fig. 8 shows promise for reducing total harmonic distortion at the generator [7][8]. The inverter consists of a three-phase low pass input filter, an input switch, a resonant or central capacitor, an output switch, a three-phase low pass output filter assembly, and the control system. This inverter is capable of producing input and output current waveforms with a total harmonic distortion (THD) of less than $2 \%$. It can operate with a near unity input power factor and with efficiencies of up to $98 \%$ and power densities of 2 $5 \mathrm{MW} / \mathrm{m}^{3}$. 


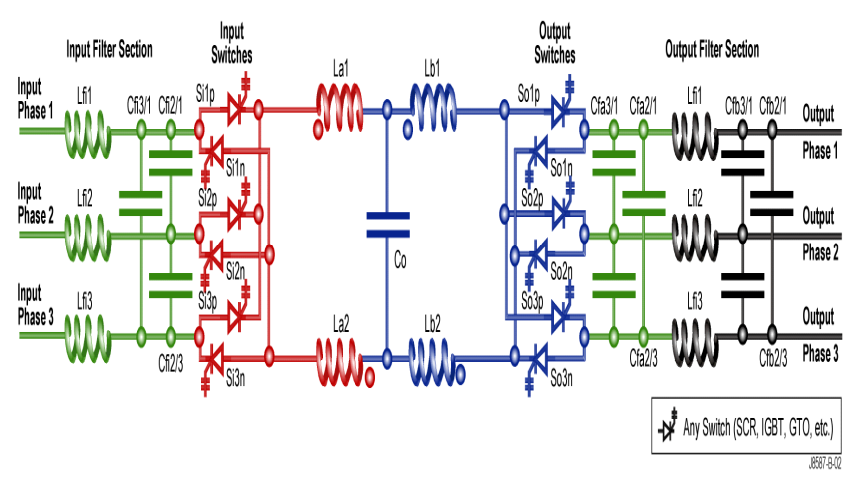

Fig. 8 Fundamental ac to ac resonant circuit.

The resonant inverter operation is divided into two operations, charge and discharge. During the charge cycle, charge is extracted from the input terminals and stored for a few microseconds in the central capacitor Co. The control system initiates the discharge cycle upon completion of the charge cycle and verification that all switch elements currents are zero. This delivers the stored energy in the central capacitor $\mathrm{Co}$ into the output terminals in the corresponding reconstruction format. For reference purposes the power flow in the circuit depicted in Fig. 8 is from left to right. The control system controls power to flow in the opposite direction, since the circuit is completely bi-directional. The charge and discharge operations are almost identical, with the discharge cycle being the inverse operation of the charge cycle. The capacitor Co is the center of operation. If an optional "Pi" input filter were selected, the circuit would have perfect symmetry.

A major difference of the Resonant inverter and other high power inverters is that it is a "soft switching" topology with no turn and turn off switching losses. In addition, the resonant inverter requires no additional galvanic isolation, such as a transformer, between the power source and the load that is required for most known inverter topologies. The switching losses are important for medium voltage application, since high voltage switches are required and become slower with higher voltage rating. IGBT and IGCT are the preferred medium voltage switches of choice.

The dominating losses for most inverters are the switch losses; the PWM has ten times the losses at $3.6 \mathrm{kHz}$ than the resonant inverter.

\subsection{Performance}

A $250 \mathrm{~kW}$ resonant converter has been built and tested. Fig. 9 and Fig. 10 show the total harmonic distortion on current remains below $2.8 \%$. Fig. 11 shows a similar conversion from $60 \mathrm{~Hz}$ to $49 \mathrm{~Hz}$ and a voltage distortion of less than $1.1 \%$. Even switching from $60 \mathrm{~Hz}$ to dc with a resonant converter introduces only a $1.8 \%$ total distortion to the current as shown in Fig. 12.

\section{Asynchronous frequency operation $60 \mathrm{~Hz}$ input to $14.6 \mathrm{~Hz}$ output}

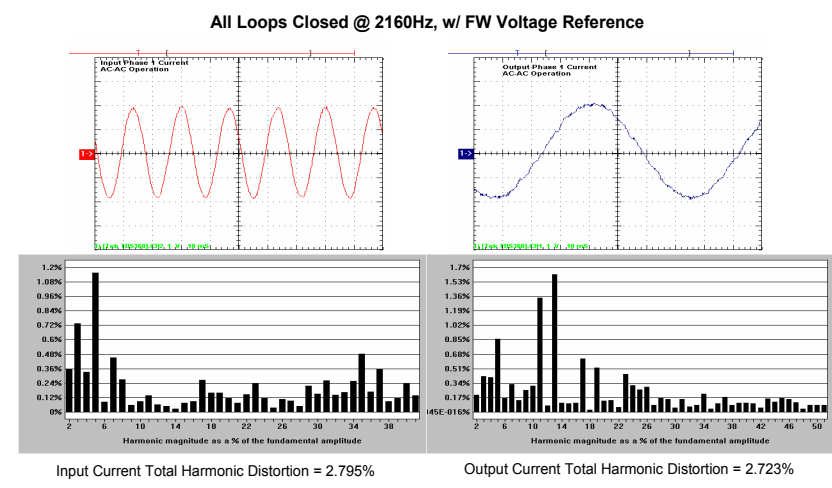

Fig. 9 The total harmonic distortion from a $60 \mathrm{~Hz}$ to 14.6 $\mathrm{Hz}$ conversion is less than $2.8 \%$.

Asynchronous frequency operation $60 \mathrm{~Hz}$ input to $85 \mathrm{~Hz}$ output

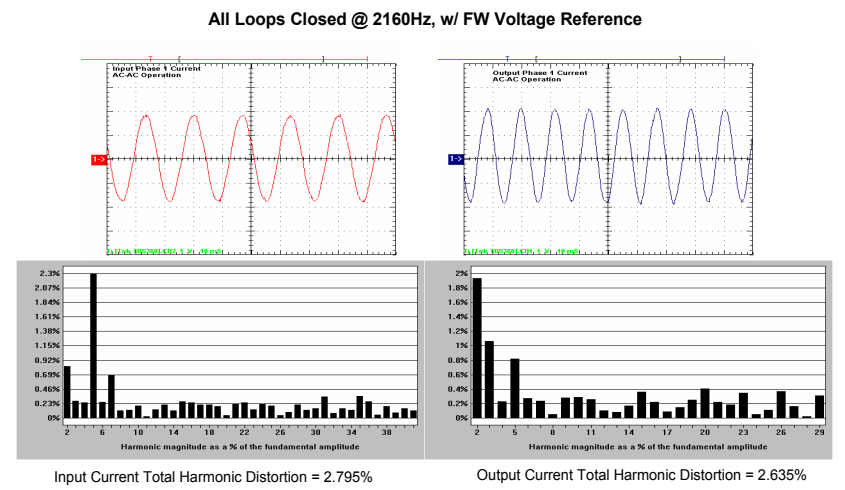

Fig. 10 Conversion from $60 \mathrm{~Hz}$ to a higher frequency, 85 $\mathrm{Hz}$.

Resonant Link INPUT WAVEFORMS
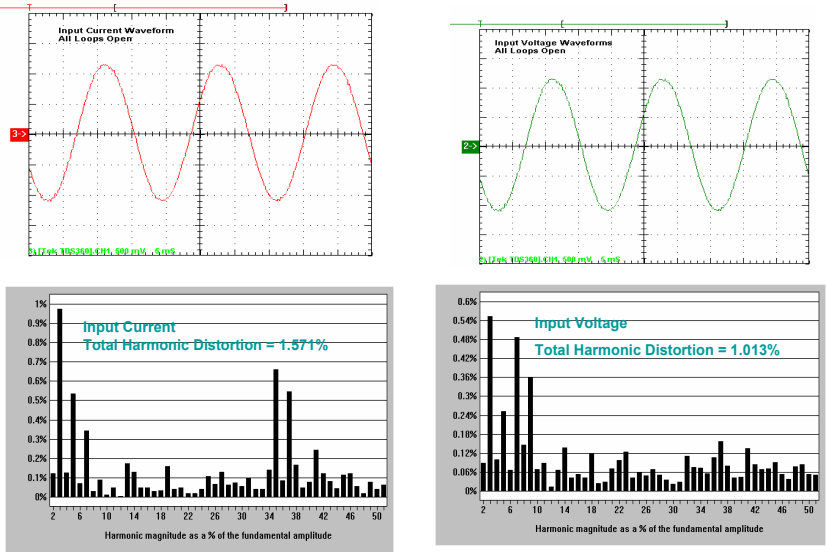

Fig. $1160 \mathrm{~Hz}$ to $49 \mathrm{~Hz}$ conversion resulting in a total harmonic distortion of $1.013 \%$ on the generator. 


\section{Asynchronous frequency operation $60 \mathrm{~Hz}$ input to DC output}

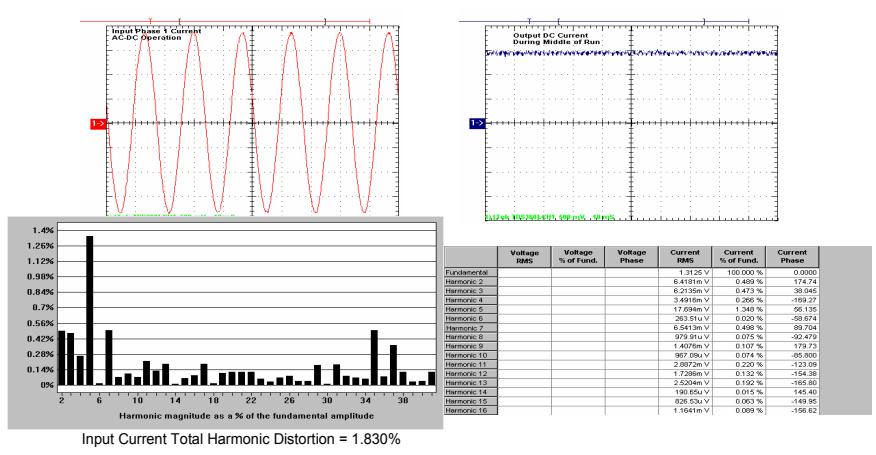

Fig. 12 Sixty $\mathrm{Hz}$ to dc conversion using a resonant converter.

\section{CONCLUSIONS}

Cutting off current through non-zero current crossings introduces voltage spikes deleterious to the life of the generator. In addition it results in generator losses both from eddy current and hysteresis sources. These two sources will result in another $1 \%$ loss in efficiency just due to rotor losses. The voltage spikes compromise the winding insulation, and the current harmonics compromise life by increased heating. It is therefore useful to index total harmonic distortion for both current and voltage. Resonant converters switch at zero crossings and thus have higher efficiencies. The total harmonic distortion is generally below $3 \%$ through a wide range of frequencies.

\section{REFERENCES}

6.

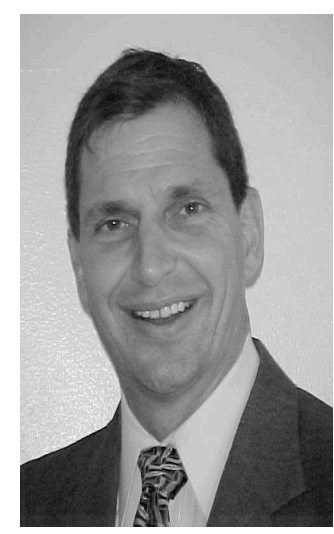

\section{BIOGRAPHIES}

Kent Davey became a Member of IEEE in 1980, a Senior Member in 1986, and a Fellow in 2004. He was born in New Orleans, Louisiana in 1952. He received his BS in EE from Tulane in 1974, his MS in Power Engineering from Carnegie Mellon in 1976, and his MS in physics from the University of Pittsburgh in 1976. $\mathrm{He}$ received his $\mathrm{PhD}$ in $\mathrm{EE}$ from the Massachusetts Institute of Technology in 1980. He completed a Fulbright in Finland on atmospheric physics in 1981. From 1974 to 1976 he worked at Westinghouse as a large turbine generator designer. From 1979 to 1980 he served as an assistant professor at Texas A\&M University. From 1980 to 1994 he served as a tenured associate professor at the Georgia Institute of Technology. From 1994 to 2002, he served as technical director of American Maglev Technology in Edgewater, Florida. He presently serves as a senior research scientist at the Center for Electromechanics at the University of Texas in Austin, Texas. Dr. Davey has research activity in electromechanical machine design, pulsed electromechanical devices,
[1] A. Cavallini, D. Fabiani, G. Mazzanti, and G.C. Montanari, "Voltage endurance of electrical components supplied by distorted voltage waveforms", International symposium on electrical insulation, Anaheim, CA, April 25, 2000, pp. 73-76.

[2] P. Pillay and M. Manyage, "Loss of life in induction machines operating with unbalanced supplies", IEEE Trans. Energy Conversion, vol. 21, no. 4, Dec. 2006, pp. 813-822.

[3] G. Skibinski and S. Breit, "Line and load friendly drive solutions for long length cable applications in electrical submersible pump applications", Fifty-First Petroleum and Chemical Industry Technical Conference, 13-15 Sept. 2004, pp. $269-278$.

[4] H. Orace and A.E. Emanuel, "Induction Motor Use and Power Quality", IEEE Power Eng. Rev., Jan. 2000, pp. 4748.

[5] Siyoung Kim, Seung-Ki Sul, and Thomas Lipo, "Ac/Ac power conversion based on matrix converter topology with unidirectional switches", IEEE Trans. Indus. Applications, vol. 36, no. 1, pp. 139-145.

[6] Vineeta Agarwal and Sachin Nema, "Resonant AC to AC Converter", IEEE ISIE Conference, Dubrovnik, Croatia, June 20-23, 2005, pp. 495-498.

[7] R. Limpaecher, et al, "Harmonic Free Rectification with Unity Power Factor for Multi-Megawatt Applications", Conf. Record of Twenty-Third Int. Modulator Symposium, 25-27 June, 1998, Palm Springs, CA

[8] R. Limpaecher, et al, "Harmonic Free New Inverter Topology for High Voltage, High Power Applications", Twenty-Fourth Int. Power Modulator Symposium, Norfolk VA, 2000.

HTS Trapped Field magnets, electroporation, and magnetic stimulation of biological tissue.

Dr. Davey is a Fellow with IEEE and presently serves as editor of IEEE Transactions on Magnetics. He is actively involved in the review of conference and journal papers for various IEEE activities.

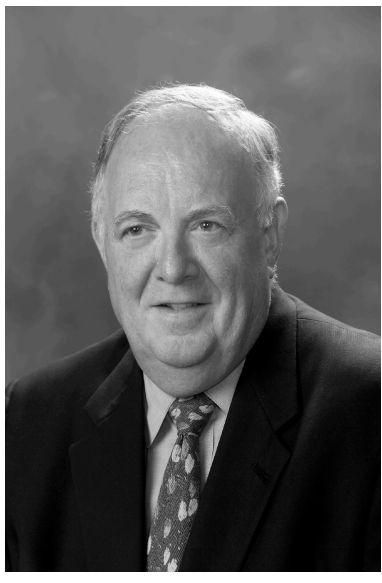

Robert E. Hebner, Ph.D., is Director of the Center for Electromechanics at the University of Texas at Austin. The Center develops technology, primarily novel motors, generators, and suspension components, and teams with companies to get the technology into the market.

Previously, Dr. Hebner was the acting Director of the U.S. National Institute of Standards and Technology (NIST). In addition, he has directed NIST's Electronic and Electrical Engineering Laboratory, a laboratory with a staff of more than 250. He also worked at the Defense Advanced Research Projects Agency where he developed programs to improve semiconductor manufacturing. 
Throughout his career, Dr. Hebner has been active in having authored or coauthored more than one hundred technical papers and reports. He has extensive experience in international technology programs. This work included the modernization of the measurement systems needed to support global trade and the assessment of the effectiveness of government technology programs in stimulating domestic economies. 